\title{
Patients with diabetes at risk in COVID-19 pandemic
}

\author{
Réka Toth ${ }^{1}$, Mihaela Chincesan², Ovidiu Grama ${ }^{3}$, Alina Grama ${ }^{2}$ \\ ${ }^{1}$ Department of Quality Management in Healthcare Services, County Emergency Clinical \\ Hospital, Tg. Mures, Romania \\ ${ }^{2}$ Pediatrics Clinic, Emergency Clinical County Hospital, Tg. Mures, Romania \\ ${ }^{3}$ Obstetrics and Gynecology Clinic, Mures County Clinical Hospital, Tg. Mures, Romania
}

\begin{abstract}
The new coronavirus infection (COVID-19) spread rapidly from the outbreak in Wuhan, China with a wide range of clinical manifestations, from asymptomatic to fatal. Individuals from the risk factor category, including those with diabetes mellitus (DM), have a proven higher risk of developing a severe form of the disease, as well as a higher risk of mortality. Through this summary we aim to briefly review the general characteristics of COVID-19 and a special situation, namely that of infection in patients with diabetes. We addressed the potential mechanisms that may increase the susceptibility of diabetic patients to COVID-19, but also the current recommendations in Romania for diabetics in the COVID-19 pandemic. Based on current limited evidence we cannot draw conclusions. Further research on this association between COVID-19 and DM is necessary and justified.
\end{abstract}

Keywords: SARS-CoV-2, infection, COVID-19, pandemic, comorbidity, diabetes mellitus

\section{INTRODUCTION}

In December 2019, a new coronavirus, now called severe acute respiratory syndrome coronavirus 2 (SARS-CoV-2), was identified as the etiological factor of an outbreak of acute respiratory disease in $\mathrm{Wu}$ han, a city in Hubei Province, China. In February 2020, the World Health Organization (WHO) announced COVID-19 as the disease name. The infection has spread, leading the WHO to declare a public health emergency on 30 January 2020 and characterize it as a pandemic on 11 March 2020. On 05 May 2020 , were $3,517,345$ confirmed cases reported from over 210 countrie,s with 243,401 deaths (1-2).

The purpose of this paper is to provide a brief summary of the general characteristics of COVID-19, as well as a detailed description of the association between this new infectious disease and diabetes.

\section{METHOD}

A literature review was performed by searching for English-language articles indexed in PubMed and Google Scholar databases until May 4, 2020. The following keywords were used: "SARS-CoV-2", "COVID-19", "infection", "clinical features", "comorbidity", "diabetes", "prognosis". We accessed the scientific recommendations and articles currently available on the websites of the WHO, the European and United States Centers for Disease Control and Prevention (ECDC, respectively CDC) and the National Institute of Public Health in Romania.

\section{General features of COVID-19}

Etiology. The coronavirus that causes COVID-19 is a beta-coronavirus of the same subgenus as Severe Acute Respiratory Syndrome (SARS) virus (as well 
as several bat coronaviruses), but in a distinct class. The structure of the gene region that binds to the receptor is very similar to that of the SARS coronavirus and it has been shown that the virus uses the same receptor, the angiotensin converting enzyme 2 (ACE2), to enter cells (3). The "Coronavirus Study Group" for virus taxonomy has proposed that this virus be designated severe acute respiratory syndrome coronavirus 2 (SARS-CoV-2) (4).

Epidemiology - distribution, route of transmission. Cases are reported from all continents, except Antarctica and are constantly growing worldwide. Enlarged local transmission clusters can now be found in Western Europe, United States and Iran. The cumulative incidence varies by country and probably depends on a number of factors, such as demographics and population density, testing and reporting, prevention and control strategies.

At the beginning of the outbreak, the epidemiological survey from Wuhan identified an initial association with a seafood market selling live animals, where most patients worked or were visitors (5). However, as the outbreak progressed, person-to-person transmission became the main mode of transmission, but the exact mode is unclear. Transmission is thought to occur, as with other respiratory pathogens including influenza and rhinovirus, through respiratory drops from coughing and sneezing (6). The virus released from the respiratory secretions of an infected person can infect another person if it makes direct contact with the mucous membranes; infection can also occur if a person touches an infected surface and then touches their eyes, nose or mouth. The drops usually do not spread more than about two meters and do not persist in the air. It is controversial whether SARSCoV-2 can be transmitted by air under natural conditions, but the direct relevance and clinical implications of these findings are unclear. Aerial precautions remain recommended when performing aerosol generating procedures (7-15). The duration of viral shedding varies significantly and possibly depends on the severity. SARS-CoV-2 can be transmitted before the onset of symptoms and during the disease (16-19). The risk of transmission from an individual with SARS-CoV-2 infection varies depending on the type and duration of exposure, the use of preventive measures, and probable individual factors (for exemple, the amount of virus in respiratory secretions). Most secondary infections have been described among household contacts, in care or healthcare facilities when personal protective equipment has not been used, and indoors (cruise ships). Social or labour gatherings are also at risk of transmission through restricted contact (20-23). The virus present on contaminated surfaces can be another source of infection. The frequency and relative importance of this type of transmission remains unclear. It may be more likely a potential source of infection in certain circumstances (for example, in the household of an infected person or in hospitals) $(7,9,24-28)$.

Clinical features. Patients with COVID-19 have presented a wide range of clinical forms, from asymptomatic / mild symptoms to serious illness and death. Symptoms may appear 2-14 days after viral exposure, and are as follows: coughing, shortness of breath or respiratory failure, fever, chills, muscle pain, sore throat, new loss of taste or smell. Other uncommon symptoms have been reported, such as gastrointestinal symptoms (nausea, vomiting or diarrhea) (29). Children have similar symptoms to adults and generally have mild manifestations, although cases have been reported - children with severe forms of COVID-19 and two deaths (30-34). Severe disease occurs predominantly in older adults or in adults with underlying medical comorbidities.

An analysis based on data from within and outside of China shows that age is a strong gradient in the risk of death. Similarly, the hospitalization rate increased with age, with a rate of $1 \%$ for $20-29$ year olds, $4 \%$ for $50-59$ year olds and $18 \%$ for $>80$ year olds (35). Older age is also associated with increased mortality. Case fatality rates have been reported in Italy from 12.8 to $20.2 \%$ among those aged $70-79$ years and $\geq 80$ years, respectively (36.37).

The established epidemiological risk factors are: age $>65$ years, pre-existing lung disease, chronic kidney disease, DM, history of hypertension, history of cardiovascular disease (CVD), obesity (BMI $\geq 30$ ). Possible risk factors include: use of biological substances (ex. TNF inhibitors, interleukin inhibitors, anti-B-cell agents), history of transplantation or other immunosuppressive conditions and HIV, CD4 cell count $<200$ cells/ $\mu 1$ or unknown CD 4 count. The CDC also includes liver disease as potential risk factors for severe disease $(20,38)$. Males accounted for a higher number of deaths in cohorts in China, Italy, and the United States (36, 39-40). Poor prognosis was also associated with some particular laboratory characteris- 
tics, such as: lymphopenia, elevated liver enzymes, elevated LDH, elevated acute phase reactants (for ex. C-reactive protein, ferritin), elevated D-dimer $(>1 \mu \mathrm{g} / \mathrm{ml})$, increased prothrombin time, elevated troponin, elevated creatine phosphokinase, acute kidney damage (20).

Diagnosis of COVID-19 infection. Testing patients, which meets the criteria set by WHO and government, can be performed in state public health laboratories, hospitals and some commercial laboratories. Reverse transcription polymerase chain reaction (RTPCR) for COVID-19 virus is the standard method for initial diagnosing virus from respiratory samples (oropharyngeal and nasopharyngeal swabs) and lower respiratory tract samples (sputum), in patients with productive cough (41).

SARS-CoV-2 invades the respiratory tract and lungs, leading to a new type of viral pneumonia (42), in which severe cases can progress rapidly to respiratory distress syndrome, septic shock, and multiple organ dysfunction syndrome (43). We do not address case management and preventive measures in this study. Individuals from the risk factor category mentioned above have a higher demonstrated risk of developing a severe form of the disease as well as a higher risk of mortality (16,44-45).

Below we will summarize a special situation, that of SARS-CoV-2 infection in patients with DM, the impact between the two global pandemics, being a gloomy reality the fact that $\mathrm{DM}$ is the second most common comorbidity in COVID-19 disease (16).

\section{ASSOCIATION BETWEEN COVID-19 AND DM}

Rates of diabetes in patients infected with SARS$\mathrm{CoV}$-2. Rates of type 2 diabetes mellitus (T2D) in patients with COVID-19 vary with age, studied population, disease severity and test method. In a report from China, diabetes was present in about $15 \%$ of 1099 patients (children and adults) hospitalized with a laboratory-confirmed diagnosis (43). Analysis of a randomly selected subset of fatal cases of COVID-19 in Italy (mean age 79.5 years) revealed a $35 \%$ prevalence of diabetes (36). In a publication from 3 April 2020 in the United States with 7,162 confirmed cases of COVID-19 (between Feb. 12 and March 28, 2020), and listed by the CDC examining comorbidities, diabetes was ranked first in frequency (10.9\%), of which $6 \%$ not hospitalized, $24 \%$ hospitalized in non-inten- sive care units, respectively $32 \%$ hospitalized in intensive care units (49). In Romania, on May 5, 2020, out of 803 deaths, 243 (30.3\%) had diabetes as a comorbidity. We mention that the prevalence of DM in Romania according to the PREDATORR study is $11.6 \%$ (50).

Susceptibility to infections in patients with DM. It is widely accepted both in medicine and by the general public that diabetics have an increased tendency to develop infections. Although several epidemiological studies have shown that diabetics receive treatment for infections more often than non-diabetics (46), the extent of the effect of diabetes on the risk of COVID-19 infection remains an active research question. A study from Netherlands evaluated the number of patients with T2D cared for in a general practice over a two-year period. A total of 458 infections were present in 193 patients, with an average of $2.4( \pm 1.9)$ infections per patient (47). Torres et al. summarize in their study that patients with diabetes have an increased risk of up to 1.4 (OR) for community-acquired pneumonia. The risk of hospitalization related with diabetes-associated pneumonia was also higher in those without other comorbidities and in those with a longer duration of diabetes and/or poor glycemic control (based on hemoglobin A1C levels) (48). Most, but not all, studies suggest that the risk of infection in diabetes is associated with hyperglycemia or lack of control of DM. For example, Critchley et al. demonstrate the strong association, but the report from the Netherlands mentioned above, with the limitations of the study, concludes that hyperglycemia is more likely to be a result than a cause of common infections $(47,49)$.

Potential mechanisms that may increase the susceptibility of patients with diabetes to COVID-19 include: 1 ) higher affinity cellular binding and efficient virus entry, 2) decreased viral clearance, 3) diminished $\mathrm{T}$ cell function, 4) increased susceptibility to hyperinflammation and "cytokine storm" syndrome and 5) the presence of CVD (51).

SARS-CoV-2 uses ACE2 receptors for entry into target cells and increased ACE2 expression has been demonstrated in lungs, kidneys, heart and pancreas in rodent models with DM $(3,52-53)$. Insulin administration attenuates ACE2 expression, while hypoglycemic agents (e.g. glucagon-like peptide-1 receptor agonist, thiazolidinediones), ACE inhibitors and statins regulate ACE2 (51). Rao et al. explored diseases or traits that may be causally linked to increased ACE2 
expression in the lung. They found that DM was causally associated with increased pulmonary ACE2 expression (54). Otherwise circulating levels of furin (cellular protease involving viral entry) are elevated in patients with DM (55).

Analyzing demographic, clinical and laboratory data of 106 patients hospitalized in a Wuhan hospital between 5 January and 25 February 2020 to identify factors influencing SARS-CoV-2 clearance negatively, Chen et al. found that advanced age, male gender and ACE2 associated factors (including hypertension, DM and CVD) adversely affected viral clearance (56).

Humans and mice with T2D exhibit a switch from predominately regulatory or anti-inflammatory macrophages and regulatory $\mathrm{T}$ cells in adipose tissue into predominately proinflammatory macrophages and Th1 cells (T helper type 1) and Th17 CD4 ${ }^{+} \mathrm{T}$. Kulcsar et al. examined the effects of DM in a humanized mouse model infected with MERS-CoV on a high-fat diet. The disease was more severe and prolonged in diabetic and male mice, and was characterized by altered $\mathrm{CD}^{+} \mathrm{T}$ cell counts and abnormal cytokine responses (elevated IL17a values). This altered immune profile is thought to contribute to a variety of consequences associated with T2D, including increased susceptibility to infections (57). Epidemiological studies indicate that $\mathrm{T} 2 \mathrm{D}$ was the main comorbidity associated with severe or fatal MERS-CoV infections (58). Regarding the current pandemic, COVID-19 $\mathrm{DM}$ is the second most common comorbidity (16).

Plasma levels of inflammatory biomarkers (interleukin-6, serum ferritin, C-reactive protein) and Ddimer are higher in patients with COVID-19 and DM compared to those without, suggesting that diabetics are more susceptible to the "cytokine storm", leading to rapid deterioration of the disease (59).

Considering increased prevalence of CVD, obesity and hypertension in diabetic patients, it is not known whether diabetes independently contributes to this increased risk of severe SARS-CoV-2 infection. However, plasma glucose levels and DM are independent predictors of mortality and morbidity in patients with SARS (60).

Challenges for clinicians and diabetics. In view of the current situation, the lack of solid scientific evidence and specific treatment, COVID-19 has become a global health problem. Currently quarantine, isolation, social distancing and strict restrictions on inter- nal and international travel are the most effective preventive strategies, along with the practice of good hygiene. These measures are likely to have an impact on worsening glucose control: limiting the physical activity of people with diabetes; restricting food deliveries during quarantine would have forced diabetics to change their eating habits that were earlier associated with good glycemic control; the purchase of anti-diabetic drugs and blood glucose test strips would have been difficult due to restrictions, as was the possibility to visit doctors for routine follow-up (61). For such situations, it is very important to educate and support the self-management of diabetes. Clinicians, on the other hand, need to be proactive in responding to the needs of patients using telemedicine, including voice or video calls, if available. It is possible that regulating care through these technologically advanced means may have a lasting impact on how diabetics are treated and follow up in the long-term (62).

Specific recommendations for people with diabetes offered by the Romanian Federation of Diabetes, Nutrition and Metabolic Diseases are as follows: reducing the number of people they come in contact with; avoiding contact with people suspected of acute respiratory infections; travel reductions; cleaning hazardous surfaces with chlorine or alcohol based disinfectants; individual hygiene measures, avoiding to touch the face, eyes, nose and mouth; washing hands very often with soap and water (minimum 20 seconds) and necessarily before using the glucometer and injecting insulin or other injectable medication; use of protective masks; not using antiviral drugs and antibiotics, unless your doctor prescribes it; maintaining contact with the diabetologist and the family doctor for planning the visit / prescription of medication and establishing the method by which you get in possession of the prescription / medication; providing sufficient medication, including comorbidity medication (3 months) and sufficient blood glucose monitoring tests to avoid interruptions in administration; when there are problems in the supply of pharmacies with antidiabetic medication, contacting the diabetologist to replace the medication; glycemic control by following lifestyle and medication recommendations; compliance with dietary recommendations; 7-8 hours sleep per night; physical activity at home; ensuring that the control and treatment of hypoglycaemia (sugar at hand) is possible; ensuring the necessities in case of self-isolation / quarantine / illness; list of contacts 
and telephone numbers (family members, family doctor, diabetologist), followed treatment and medication to be available in case of emergency or illness (63).

\section{CONCLUSIONS}

COVID-19 has spread rapidly from the outbreak in Wuhan, China and has a wide range of clinical manifestations. Isolation, early diagnosis and associ-

\section{REFERENCES}

1. World Health Organization. Coronavirus disease (COVID-19) Pandemic 2020 [05/05/2020]. Available from: https://www.who.int/ emergencies/diseases/novel-coronavirus-2019/situation-reports/ (Accessed on 6 May 2020).

2. World Health Organization. Rolling updates on coronavirus disease (COVID-19) 2020 [05/05/2020]. Available from: https://www.who.int/ emergencies/diseases/novel-coronavirus-2019/events-as-they-happen.

3. Zhou P, Yang XL, Wang XG et al. A pneumonia outbreak associated with a new coronavirus of probable bat origin. Nature 2020;579:270.

4. Gorbalenya AE et al. Severe acute respiratory syndrome-related coronavirus - the species and its viruses, a statement of the Coronavirus Study Group. Preprint at https://www.biorxiv.org/content/ 10.1101/2020.02.07.937862v1 (2020).

5. World Health Organization. Novel coronavirus situation report-2. January 22, 2020. https://www.who.int/docs/default-source/ coronaviruse/situation-reports/20200122-sitrep-2-2019-ncov.pdf (Accessed on 6 May 2020).

6. CDC. 2019 Novel Coronavirus, Wuhan, China: Frequently Asked Questions and Answers. CDC. Available at https://www.cdc.gov/ coronavirus/2019-ncov/faq.html. January 27, 2020 (Accessed on 6 May 2020).

7. van Doremalen N, Bushmaker T, Morris DH et al. Aerosol and Surface Stability of SARS-CoV-2 as Compared with SARS-CoV-1. N Engl J Med. 2020;382:1564.

8. Guo ZD, Wang ZY, Zhang SF et al. Aerosol and Surface Distribution of Severe Acute Respiratory Syndrome Coronavirus 2 in Hospital Wards, Wuhan, China, 2020. Emerg Infect Dis. 2020;26.

9. Ong SWX, Tan YK, Chia PY et al. Air, Surface Environmental, and Personal Protective Equipment Contamination by Severe Acute Respiratory Syndrome Coronavirus 2 (SARS-CoV-2) From a Symptomatic Patient. JAMA. 2020.

10. Bahl P, Doolan C, de Silva $C$ et al. Airborne or droplet precautions for health workers treating COVID-19? J Infect Dis. 2020.

11. Liu $Y$, Ning $Z$, Chen $Y$ et al. Aerodynamic analysis of SARS-CoV-2 in two Wuhan hospitals. Nature. 2020.

12. Wong SC, Kwong RT, Wu TC et al. Risk of nosocomial transmission of coronavirus disease 2019: An experience in a general ward setting in Hong Kong. $J$ Hosp Infect. 2020.

13. $\mathrm{Ng} \mathrm{K}$, Poon BH, Kiat Puar TH et al. COVID-19 and the Risk to Health Care Workers: A Case Report. Ann Intern Med. 2020

14. Bourouiba L. Turbulent Gas Clouds and Respiratory Pathogen Emissions: Potential Implications for Reducing Transmission of COVID-19. JAMA. 2020.

15. Lu J, Gu J, Li K et al. COVID-19 Outbreak Associated with Air Conditioning in Restaurant, Guangzhou, China, 2020. Emerg Infect Dis. 2020;26.

16. Zhou F, Yu T, Du R, Fan G, Liu Y, Liu Z et al. Clinical course and risk factors for mortality of adult inpatients with COVID-19 in Wuhan, China: A retrospective cohort study. Lancet. 2020.

17. Liu Y, Yan LM, Wan L, Xiang TX, Le A, Liu JM et al. Viral dynamics in mild and severe cases of COVID-19. Lancet Infect Dis. 2020.

18. Zheng S, Fan J, Yu F et al. Viral load dynamics and disease severity ated management bring better control of the disease.

$\mathrm{DM}$, as a comorbidity, is shown to be a predictor of morbidity and mortality.

Social distancing, strict hygiene, good self-management of diabetes and communication with the diabetes specialist are very important in the COVID-19 pandemic.

\section{Conflict of interest: none declared Financial support: none declared}

in patients infected with SARS-CoV-2 in Zhejiang province, China, January-March 2020: Retrospective cohort study. BMJ. 2020;369:m1443.

19. Xu K, Chen Y, Yuan J et al. Factors associated with prolonged viral RNA shedding in patients with COVID-19. Clin Infect Dis. 2020.

20. Kenneth Mclntosh. Coronavirus disease 2019 (COVID-19): Epidemiology, virology, clinical features, diagnosis, and prevention. In: UpToDate, Post, TW (Ed), UpToDate, Waltham, MA, 2020.

21. McMichael TM, Clark S, Pogosjans S et al. COVID-19 in a LongTerm Care Facility - King County, Washington, February 27-March 9, 2020. MMWR Morb Mortal Wkly Rep 2020;69:339.

22. $\mathrm{Ng} \mathrm{D}, \mathrm{Hu} \mathrm{B}, \mathrm{Hu} \mathrm{C}$ et al. Clinical Characteristics of 138 Hospitalized Patients With 2019 Novel Coronavirus-Infected Pneumonia in Wuhan, China. JAMA. 2020.

23. Kakimoto K, Kamiya H, Yamagishi T et al. Initial Investigation of Transmission of COVID-19 Among Crew Members During Quarantine of a Cruise Ship - Yokohama, Japan, February 2020. MMWR Morb Mortal Wkly Rep. 2020; 69:312.

24. Yung CF, Kam KQ, Wong MSY et al. Environment and Personal Protective Equipment Tests for SARS-CoV-2 in the Isolation Room of an Infant With Infection. Ann Intern Med 2020.

25. Kampf G, Todt D, Pfaender S, Steinmann E. Persistence of coronaviruses on inanimate surfaces and their inactivation with biocidal agents. J Hosp Infect. 2020; 104:246.

26. Rabenau HF, Cinatl J, Morgenstern B et al. Stability and inactivation of SARS coronavirus. Med Microbiol Immunol. 2005; 194:1.

27. Otter JA, Donskey C, Yezli S et al. Transmission of SARS and MERS coronaviruses and influenza virus in healthcare settings: the possible role of dry surface contamination. J Hosp Infect. 2016; 92:235.

28. Wölfel R, Corman VM, Guggemos W et al. Virological assessment of hospitalized patients with COVID-2019. Nature. 2020

29. CDC. 2019 Novel Coronavirus, Wuhan, China: Symptoms. CDC. Available at https://www.cdc.gov/coronavirus/2019-ncov/about/ symptoms.html. January 26, 2020; (Accessed on 6 May 2020).

30. Wu Z, McGoogan JM. Characteristics of and Important Lessons From the Coronavirus Disease 2019 (COVID-19) Outbreak in China: Summary of a Report of 72314 Cases From the Chinese Center for Disease Control and Prevention. JAMA. 2020 Feb 24.

31. Dong $Y, M o X, H u Y, Q i X$, Jiang $F$, Jiang $Z$ et al. Epidemiological Characteristics of 2143 Pediatric Patients With 2019 Coronavirus Disease in China. Pediatrics. 2020.

32. Qiu H, Wu J, Hong L, Luo Y, Song Q, Chen D. Clinical and epidemiological features of 36 children with coronavirus disease 2019 (COVID-19) in Zhejiang, China: An observational cohort study. Lancet Infect Dis. 2020.

33. Shelley Riphagen, Xabier Gomez, Carmen Gonzalez-Martinez et al. Hyperinflammatory shock in children during COVID-19 pandemic. Published online: May 06, 2020. Available at: https://www.thelancet. com/action/showPdf?pii=S0140-6736\%2820\%2931094-1 (Accessed on: 09 May 2020).

34. https://www.worldometers.info/coronavirus/ (Accessed on 9 May 2020).

35. Verity R, Okell LC, Dorigatti I et al. Estimates of the severity of coronavirus disease 2019: a model-based analysis. Lancet Infect Dis 2020. 
36. Onder G, Rezza G, Brusaferro S. Case-Fatality Rate and Characteristics of Patients Dying in Relation to COVID-19 in Italy. JAMA. 2020.

37. Report of the WHO-China Joint Mission on Coronavirus Disease 2019 (COVID-19). Published February 16, 2020. Available at: https:// www.who.int/docs/default-source/coronaviruse/who-china-joint-mission-on-covid-19-final-report.pdf (Accessed on 9 May 2020).

38. Centers for Disease Control and Prevention. People who are at higher risk for severe illness https://www.cdc.gov/coronavirus/2019ncov/need-extra-precautions/people-at-higher-risk.html (Accessed on 9 May 2020).

39. Chen $T, W u D, C h e n ~ H$ et al. Clinical characteristics of 113 deceased patients with coronavirus disease 2019: retrospective study. BMJ 2020:368:m1091.

40. Richardson S, Hirsch JS, Narasimhan M et al. Presenting Characteristics, Comorbidities, and Outcomes Among 5700 Patients Hospitalized With COVID-19 in the New York City Area. JAMA. 2020.

41. World Health Organization. Coronavirus disease (COVID-19) technical guidance: Laboratory testing for 2019-nCoV in humans 2020. Available from: https://www.who.int/emergencies/diseases/ novel-coronavirus-2019/technicalguidance/laboratory-guidance (Accessed on 9 May 2020).

42. Zhu N, Zhang D, Wang W et al.; China Novel Coronavirus Investigating and Research Team. A novel coronavirus from patients with pneumonia in China, 2019. N Engl J Med. 2020;382:727-733.

43. Guan WJ, Ni ZY, Hu Y et al.; China Medical Treatment Expert Group for COVID-19. Clinical characteristics of coronavirus disease 2019 in China. N Engl J Med. 2020.

44. Wang D, Hu B, Hu C et al. Clinical characteristics of 138 hospitalized patients with 2019 novel coronavirus-infected pneumonia in Wuhan, China. JAMA. 2020.

45. Zhang $P, Z$ Zhu L, Cai J et al. Association of inpatient use of angiotensin converting enzyme inhibitors and angiotensin II receptor blockers with mortality among patients with hypertension hospitalized with COVID-19. Circ. Res. 2020.

46. Mor A, Berencsi K, Nielsen JS et al. Rates of Community-based Antibiotic Prescriptions and Hospital-treated Infections in Individuals With and Without Type 2 Diabetes: A Danish Nationwide Cohort Study, 2004-2012. Clin Infect Dis 2016;63:501.

47. Bartelink ML, Hoek L, Freriks JP, Rutten GE. Infections in patients with type 2 diabetes in general practice. Diabetes Res Clin Pract 1998:40:15

48. Torres A, Blasi F, Dartois $\mathrm{N}$ et al. Which individuals are at increased risk of pneumococcal disease and why? Impact of COPD, asthma, smoking, diabetes, and/or chronic heart disease on communityacquired pneumonia and invasive pneumococcal disease. Thorax. 2015 Oct. 70 (10):984-9.
49. Team CC-R. Preliminary estimates of the prevalence of selected underlying health conditions among patients with coronavirus disease 2019 - United States, February 12-March 28, 2020. MMWR Morb Mortal Wkly Rep 2020;69:382-386.

50. Mota M, Popa SG, Mota E et al. Prevalence of diabetes mellitus and prediabetes in the adult Romanian population: PREDATORR study. $J$ Diabetes. 2016;8(3):336-44.

51. Muniyappa R, Gubbi S. COVID-19 Pandemic, Corona Viruses, and Diabetes Mellitus. Am J Physiol Endocrinol Metab. 2020.

52. Roca-Ho H, Riera M, Palau V et al. Characterization of ACE and ACE2 Expression within Different Organs of the NOD Mouse. Int $J$ Mol Sci. 2017;18:563.

53. Wysocki J, Ye M, Soler MJ et al. ACE and ACE2 activity in diabetic mice. Diabetes. 2006;55:2132-39.

54. Rao S, Lau A, So H-C. Exploring diseases/traits and blood proteins causally related to expression of ACE2, the putative receptor of 2019- nCov: A Mendelian randomization analysis (Preprint). medRxiv:2020.2003.2004.20031237.

55. Fernandez C, Rysä J, Almgren P et al. Plasma levels of the proprotein convertase furin and incidence of diabetes and mortality. $\mathrm{J}$ Intern Med. 2018;284:377-87.

56. Chen $X$, Hu W, Ling J, Mo $P$ et al. Hypertension and diabetes delay the viral clearance in COVID-19 patients (Preprint). medRxiv: 2020.2003.2022.20040774.

57. Kulcsar KA, Coleman CM, Beck SE, Frieman MB. Comorbid diabetes results in immune dysregulation and enhanced disease severity following MERS-CoV infection. JCl Insight. 2019;4(20):e131774.

58. Alqahtani FY, Aleanizy FS, Ali El Hadi Mohamed R et al. Prevalence of comorbidities in cases of Middle East respiratory syndrome coronavirus: A retrospective study [published online ahead of print, 2018 Nov 5]. Epidemiol Infect. 2018;147:1-5.

59. Guo W, Li M, Dong Y et al. Diabetes is a risk factor for the progression and prognosis of COVID-19 [published online ahead of print, 2020 Mar 31]. Diabetes Metab Res Rev. 2020;e3319.

60. Yang JK, Feng Y, Yuan MY et al. Plasma glucose levels and diabetes are independent predictors for mortality and morbidity in patients with SARS. Diabet Med. 2006;23:623-628.

61. Banerjee M, Chakraborty S, Pal R. Diabetes self-management amid COVID-19 pandemic. Diabetes Metab Syndr. 2020;14(4):351-354.

62. Angelidi AM, Belanger MJ, Mantzoros CS. Commentary: COVID-19 and diabetes mellitus: What we know, how our patients should be treated now, and what should happen next. Metabolism. 2020;107:154245.

63. Ghidul pentru persoanele cu diabet în perioada epidemiei de coronavirus. Available at: http://fadr.ro/wp-content/uploads/2016/07/ GHID-diabet-si-coronavirus-2020.pdf (Accessed on 13 May 2020). 